\title{
Семенова Я.О.
}

Понятие и значение юридических сроков в гражданском праве

Уральский институт управления - филиал ФГБОУ ВО "Российская академия народного хозяйства и государственной службы при Президенте Российской Федерации"

(Россия, Екатеринбург)

doi: 10.18411/trnio-10-2021-120

\section{Аннотация}

В статье проводится анализ правовых норм, закрепляющих особенности сроков в гражданском праве, чтобы сформулировать определение понятия «срок». В силу комплексности института сроков в гражданском праве для его изучения целесообразно применить классификационный метод для выявления основных групп сроков. В статье раскрывается значение сроков для гражданского оборота посредством их рассмотрения в качестве юридических фактов. Истечение срока является юридическим фактом в силу того, что при его наступлении возникают, изменяются или прекращаются гражданские правоотношения. Сроки в гражданском праве имеют особое значение, так как они указывают на момент, в который должны быть совершены определенные действия, а также дисциплинируют участников гражданского оборота. Сроки в гражданских правоотношениях выступают в качестве элемента обязательства, который обеспечивает защиту прав и законных интересов участников правоотношений.

Теоретические исследования показывают, что нормативные положения о сроках должны быть усовершенствованы с целью конкретизировать соотношение понятий «истечение срока договора» и «истечение срока обязательства. Для исследования используются не только теоретические изыскания цивилистов, но и материалы судебной практики. На основе анализа судебных решений делаются выводы, значимые для понимания объективного значения сроков для гражданского оборота.

Кроме классификационного метода в исследовании используются методы дедукции и индукции, метод ретроспективного анализа, системный метод, логический метод, метод лингвистического анализа правовых норм и некоторые другие методы.

Ключевые слова: срок исполнения обязательства, срок действия договора, юридический факт, гражданское правоотношение, должник, кредитор, просрочка исполнения обязательства, срок исковой давности, разумный срок.

\section{Abstract}

The article analyzes the legal norms that fix the peculiarities of terms in civil law in order to formulate the definition of the term "term". Due to the complexity of the institution of terms in civil law, for its study, it is advisable to apply the classification method to identify the main groups of terms. The article reveals the meaning of terms for civil turnover by considering them as legal facts. The expiration of the term is a legal fact due to the fact that when it occurs, civil relations arise, change or terminate. Terms in civil law are of particular importance, since they indicate the moment at which certain actions must be performed, and also discipline the participants in civil turnover. Terms in civil legal relations act as an element of the obligation, which ensures the protection of the rights and legitimate interests of the participants in legal relations.

Theoretical studies show that the regulatory provisions on timing should be improved in order to specify the relationship between the concepts of "expiration of the contract" and "expiration of the term of the obligation. For the study, not only the theoretical research of civilians is used, but also the materials of judicial practice. Based on the analysis of court decisions, conclusions are drawn that are significant for understanding the objective value of the terms for civil turnover. 
In addition to the classification method, the study uses the methods of deduction and induction, the method of retrospective analysis, the systemic method, the logical method, the method of linguistic analysis of legal norms and some other methods.

Keywords: the term for the performance of the obligation, the term of the contract, the legal fact, the civil relationship, the debtor, the creditor, the delay in the performance of the obligation, the limitation period, a reasonable period.

Для реализации субъективных прав и исполнения обязательств всегда предоставляются определенные сроки. Законодатель учитывает особенности правоотношений и в соответствии с ними устанавливает сроки, достаточные для того, чтобы уполномоченный субъект имел реальную возможность для использования своего права или для исполнения обязательства.

Сроки являются юридическими фактами. Даже если в сделках стороны согласуют сроки исполнения обязательств, наступление сроков не зависит от воли сторон. В научной литературе высказывается мнение о том, что сроки являются особой разновидностью юридических фактов, которые нельзя отнести ни к фактам-действиям, ни к фактамсобытиям.

С мнением Т.Г. Петрухина трудно согласиться, так как срок - это отрезок времени, окончание которого указывается в точных показателях или обозначается определенным событием. Нет необходимости изобретать «особый» вид юридических фактов, чтобы определить понятие и сущность срока. В гражданском праве под сроком понимается промежуток времени, в течение которого могут быть осуществлены какие-то действия, или момент, в который происходит изменение правоотношений или их прекращение.

Подходы к исчислению сроков были сформированы еще в советском гражданском законодательстве и сохранились в современном законодательстве. В Гражданском кодексе Российской Федерации (ГК РФ) в первой части закреплено более 150 норм, касающихся сроков, назначаемых для осуществления прав, исполнения обязанностей или защиты нарушенных прав.

Комплексные правовые институты обычно исследуются с применением классификационного метода. В науке гражданского права имеются многочисленные критерии, по которым может осуществляться классификация гражданско-правовых сроков. Наиболее распространенной является классификация сроков по назначению:

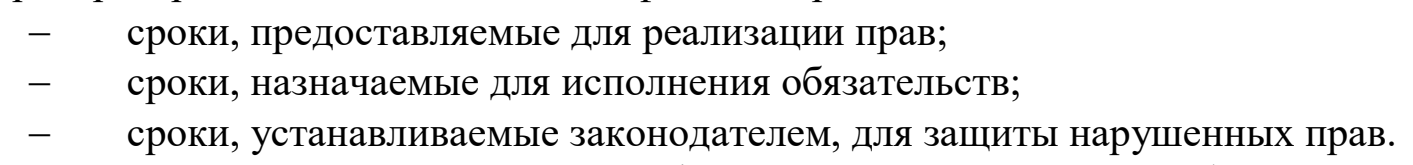

В основе срока как юридического факта лежит конкретное обстоятельство, с наступлением которого связаны определенные правовые последствия. Сама по себе дата истечения срока не имеет правового значения. Момент истечения срока становится юридическим фактом, если с этим моментом связаны последствия юридического характера. Так, в договоре может быть указан момент, в который прекращается договор, или прекращается обязательство. Прекращение обязательства отличается от прекращения договора тем, что обязательство прекращается в момент его полного исполнения, но при этом договор может продолжать действовать, если в нем специально не установлено, что договор прекращается вместе с прекращением обязательства.

По договору энергоснабжения и договору аренды, заключенных на определенный срок, истечение срока не имеет правовых последствий, потому что при отсутствии желания у сторон прекратить правоотношения, действие договоров продолжается. Названные договоры могут быть прекращены по инициативе одной из сторон с соблюдением специальной процедуры, установленной законом.

Это говорит о том, что срок не всегда является юридическим фактом, влекущим изменение или прекращение правоотношений. По договору аренды наступление срока может 
быть элементом юридического состава, в содержание которого входит не только истечение срока, но и определенные действия сторон.

В этом вопросе нужно согласиться с выводами А.В. Кострубы, который рассматривает истечение срока в качестве самостоятельного юридического факта только в тех случаях, когда об этом прямо указано в законе или договоре. В таких случаях установление срока выполняет функцию указателя на определенный промежуток времени, в течение которого действуют некоторые права, или исполняются обязанности.

В соответствии с пунктом 1 части 3 статьи 425 ГК РФ в договоре должно быть закреплено условие о том, что договор прекращается вместе с обязательствами сторон. Если такого указания нет, то в соответствии с пунктом 2 части 3 статьи 425 ГК РФ договор может прекратиться, а обязательства не прекращаются до их исполнения. При отсутствии конкретного срока для исполнения обязательств, они должны быть исполнены в разумные сроки.

Спор о соотношении сроков прекращения договора и прекращения обязательства не является новым для современного гражданского законодательства. В римском праве было принято исполнять обязательство по первому требованию, если в договоре не указан срок исполнения. При несогласии должника со сроком, который устанавливал кредитор для исполнения обязательства, спор решался судьей, при этом в первую очередь учитывались интересы должника.

Процесс исполнения обязательства, о сроке которого не было указания в договоре, в римском праве был подробно урегулирован. Так, обращению к судье должна была предшествовать досудебная процедура, в ходе которой должник напоминает о долге и выясняет причины просрочки исполнения обязательства. Это важно, потому что к судье можно было обращаться только в случае неуважительности причин неисполнения обязательства. За просрочку с должника взимались проценты, либо обязательство становилось дороже, если предмет обязательства поднимался в цене за время просрочки исполнения обязательства. Ответственность должника снижалась, если просрочка наступала по вине кредитора, который без уважительных причин не принимал исполнение обязательства. Если просрочка наступала по вине кредитора, то на кредитора возлагался риск утраты предмета обязательства, а также кредитор должен был возместить затраты, которые понес должник в связи с хранением предмета обязательства.

Соблюдение сроков показывает не динамику сроков или гражданского правоотношения, а то насколько надлежащим образом исполняется обязательство. Гражданско-правовая ответственность наступает при нарушении сроков.

Судя по назначению сроков нельзя сказать, что они все могут считаться юридическими фактами. Так, в договоре строительного подряда предусмотрены промежуточные сроки, и их истечение не изменяет правоотношений, если они соблюдаются, следовательно, правовые последствия не наступают.

Применение сроков затрудняется тем, что в гражданском праве закреплена презумпция, в соответствии с которой прекращение срока действия договора не влечет прекращение обязательств, предусмотренных этим договором. Например, срок договора аренды может истечь, но арендатор должен исполнить до конца обязательства, связанные с арендой. Также может истечь срок договора поставки, но обязательства поставщика по отгрузке и передаче товаров не прекращаются вместе с договором. Срок договора и срок исполнения договорных обязательств прекращаются одновременно, если об этом специально указано в договоре.

Пленум Высшего Арбитражного Суда Российской Федерации (ВАС РФ) разъяснил, что при решении судами вопросов об исполнении обязательств по договорам, срок действия которых закончился, нужно руководствоваться нормами статьи 314 ГК РФ. Это значит, что незаконченное обязательство должно быть исполнено по первому требованию кредитора, а в случае невозможности исполнить обязательство в срок, предложенный кредитором, оно должно быть исполнено в разумные сроки. 
В статье 314 ГК РФ фактически содержится критерий для классификации сроков, которым является степень определенности срока. По данному критерию можно выделить следующие группы сроков:

- $\quad$ предельно определенные сроки (в законе или договоре указывается срок в точных количественных параметрах);

- $\quad$ относительно определенные сроки (в договоре устанавливаются какие-либо события, до которых должно быть исполнено обязательство, например, начало навигационного периода, понижение ночных температур ниже нуля и т.д.);

- р разумный срок (сроки без определения времени и событий, оцениваемые судом по внутреннему убеждению).

Сроки могут быть нарушены не только просрочкой исполнения обязательства, но и досрочным исполнением обязательства. Досрочное исполнение обязательства может повлечь ответственность для должника, если таким нарушением срока нарушаются интересы кредитора. Для досрочного исполнения обязательства в договоре должно быть специальное указание о такой возможности, или такая возможность может вытекать из существа самого обязательства. Например, обязательство по договору беспроцентного займа может быть исполнено досрочно, так как это не нарушает интересов кредитора, но досрочное исполнение кредитных обязательств является невыгодным для кредитора. Досрочное исполнение обязательства должно быть предусмотрено законом или договором. Например, в кредитном договоре предусматривается право кредитора требовать досрочного исполнения обязательства, но для этого должны быть веские основания. Кредитор может потребовать досрочного исполнения обязательства от юридического лица, которое реорганизуется или инициирует процедуру банкротства, так как повышается риск кредитора в том, что обязательство не будет исполнено надлежащим образом, или же оно вообще не будет исполнено.

Таким образом, срок в гражданском праве представляет собой некий промежуток времени, установленный законом или договором, который необходим для исполнения обязательства или реализации права. Также в качестве срока может рассматриваться момент, до наступления которого должны быть совершены определенные действия.

Истечение срока рассматривается в науке гражданского права как юридический факт, так как наступление этого момента может изменять и прекращать правовые отношения.

Сроки в гражданском праве выполняют функцию регулятора правоотношений, благодаря которому гарантируется соблюдение прав и законных интересов участников гражданского оборота, а также поведение субъектов правоотношений становится более упорядоченным и дисциплинированным. Однако правоотношения не отличаются «жесткостью», так как законодатель предусматривает категорию разумного срока, которая придает правоотношениям гибкость и динамизм.

$$
\text { *** }
$$

1. Гражданский кодекс Российской Федерации (часть первая) от 30 ноября 1994 года № 51-ФЗ (в ред. Федерального закона РФ от 28.06.2021 г. № 225-ФЗ) // Собрание законодательства РФ. - 05.12.1994. - №32. ст. 3301.

2. Евтых Р.А. Исполнение обязательств по договору после завершения его срока действия. - Тамбов: Издательство ООО «Грамота» // Исторические, философские, политические и юридические науки, культурология и искусствоведение. Вопросы теории и практики. - 2014. - №3-2(41). - С. 73 - 77.

3. Коструба А.В. К вопросу о завершении срока как правопрекращающего юридического факта и его действие в механизме правопрекращения. - Уфа: Издательство Башкирского государственного университета // Вестник Башкирского университета. - 2013. - Т. 18. - №3. - С. 924 - 927.

4. Мора Е.П., Вакиль М.В., Райкова Ю.Ю. Сроки в современном гражданском праве / Юридическая наука в XXI веке: актуальные проблемы и перспективы их решений: Сборник научных статей по итогам работы Второго круглого стола со всероссийским и международным участием. - М.: Издательство ООО «KOHBEPT», 2020. - C. $164-166 .-280$ c. 
5. Павлов Е.В., Лазарева О.В., Морозова Ю.М. Римское право: Учебное пособие. - Саранск: Издательство ИП Афанасьев Вячеслав Сергеевич, 2020. - 220 с.

6. Петрухин М.В. Проблема определения существенных условий договора участия в долевом строительстве. СПб.: Издательство Университетского издательского консорциума «Юридическая книга» // Российский ежегодник предпринимательского (коммерческого) права. - 2010. - №4. - С. 210 - 223.

7. Подгузова Е.И. История развития договорных оснований прекращения обязательств в римском праве. - М.: Издательство Института деловой карьеры // Общество и право. - 2013. - №2(6). - С. 210 - 213.

8. Постановление Пленума Высшего Арбитражного Суда Российской Федерации от 22 октября 1997 года №18 «О некоторых вопросах, связанных с применением положений Гражданского кодекса Российской Федерации о договоре поставки» // Российская юстиция. - 1998. - №4.

\section{Славова Н.А. \\ Обеспечение иска в гражданском процессе: сравнительно-правовой анализ законодательства Российской Федерации, Украины, Республики Беларусь}

Филиал Российского государственного гуманитарного университета

(Россия, Домодедово)

doi: 10.18411/trnio-10-2021-121

\section{Аннотация}

В статье исследуются вопросы обеспечения иска в гражданском судопроизводстве. Проанализированы нормы гражданско-процессуального законодательства Российской Федерации, Украины и республики Беларусь, которые регламентируют процедуру обеспечения иска в гражданском процессе.

Ключевые слова: исковое заявление, суд, гражданское судопроизводство, обеспечение иска, судебная защита, гражданско-процессуальное законодательство, зарубежный опыт.

\section{Abstract}

The article examines the issues of securing a claim in civil proceedings. The article analyzes the norms of the civil procedural legislation of the Russian Federation, Ukraine and the Republic of Belarus, which regulate the procedure for securing a claim in a civil process.

Keywords: statement of claim, court, civil proceedings, securing a claim, judicial protection, procedural legislation, foreign experience.

В соответствии со ст. 46 Конституции Российской Федерации каждому гарантируется судебная защита [1]. Реализация права на судебную защиту зависит от процессуальноправового механизма. Одним из недостатков судебного способа защиты нарушенного права является формальный подход участников судебного процесса к рассматриваемому делу, отсутствие оперативности в принятии процессуальный действий и решений и тд. Особенно печально, когда случаются ситуации, при которых нарушенное право невозможно защитить, поскольку, например, у ответчика прекращено право собственности на имущество, которое было предметом спора. В результате чего, решение суда может остаться без исполнения, и судебная защита прав и интересов истца является неэффективной (сводится к нулю).

В связи с этим, законодатель предоставляет возможность обеспечить иск путем вынесения определения о принятии мер по обеспечению иска.

Институт обеспечения иска гражданского процессуального права состоит из норм, который российский законодатель разместил в требованиях главы 13 «Обеспечение иска» Гражданского процессуального кодекса Российской Федерации (далее - ГПК РФ) [2]. Легальное определение «обеспечение иска» в законодательстве отсутствует, но в то же время законодатель определяет меры по обеспечению иска и процедуру осуществления. Легального определения так же нет и в гражданско-процессуальном законодательстве Республики Беларусь и Украины. 